\title{
A Cardiotonic Substance found in Penicillin and its Acting Mechanism
}

\author{
by \\ Kazutoshi ITO,* Masafumi KOBAYASHI* \\ and Toyoyuki TAMURA*
}

\section{Introduction}

Attention which came to be engaged in the general pharmacological actions of antibiotics in conjunction with the so-called penicillin shock necessarily brought about need for detailed examinations of other antibiotics than penicillin. As a result, it has been found that in the extreme case some of the antibiotics contain cancerogenic matter.

In dealing with shocks due to antibiotics, our usual attention is paid to their influence on the circulatory organs and heart function. NAKAZUKA et al. reported that streptomycin, chloromycetin, aureomycin and terramycin possess inhibitory effect upon the heart function and, on the other hand, only erythromycin enhances it with penicillin being neutral in this respect. TAMURA et al. read a paper before the 26th Congress of Japan Pharmacological Society concerning a substance extractable from penicillin which has the cardiotonic action. In the present inquiry, this discovery has been further pursued in which examinations are made of its acting mechanism as well as cardiac, blood pressure and respiratory effects of penicillin itself.

\section{Experimental Materials and Procedure}

\section{A. Preparation of Sample:}

We used crystalline penicillin G sodium (to be referred to as CPGS in the ensuing pages) and the cardiotonic matter, designated as corcillin (abbreviated COR.), was prepared in the manner described as below.

The bacterial refuse from which penicillin was already extracted was dried with the low temperature vacuum apparatus and its amount of $100 \mathrm{~g}$ was infused in $200 \mathrm{cc}$ methanol for 24 hours. After it was aqueezed to remove liquid off it, it was further processed through $200 \mathrm{cc}$ ether for the same length of time and squeezed again. Removal of liquid by means of two repetitions above meant to eliminate amino acid and other impure salts of penicillin soluble in alcohol.

In the final process, a sample of nearly $80 \mathrm{~g}$ was obtained and to it was added calcium hydroxide corresponding to $1 / 5$ of the sample. It was mixed and left in the air to dry in the state of dumpling. This treatment aimed at eliminating unnecessary alkali matters contained in the sample. The dried dumpling was solved in $250 \mathrm{cc}$ methanol and after being warmed for 3 hours it was subjected to extraction, the resultant

* 伊藤一利, 小林 雅交, 田村 豊幸：Dept. of Pharmacology, Nihon Univ. School of Dentistry (Director: Prof. Mikio SATO) 
liquid was concentrated into $50 \mathrm{~g}$ by heating and $150 \mathrm{cc}$ methanol was again added after filtering. At this stage, white sediment resulted in the amount of $5 \mathrm{cc}$ and after the addition to it of $50 \mathrm{cc}$ distilled water, it was left standing for 3 hours with another: addition of $1 \mathrm{~g}$ activated carbon for the purpose of decoloration. The filtrate which was transparent and colorless was treated with $20 \mathrm{cc}$ methanol and when the white sediment in the amount of $1 \mathrm{~g}$ was obtained after desiccation, it was put to service as a cardiotcnic substance for our experimental purposes.

\section{B. Method for Cardiography:}

Hearts were extracted of male and female tcads, weighing around $200 \mathrm{~g}$, with no distinction of sex and the experimental substance was dropped in the irrigating Ringer solution in conjunction with the Yagi apparatus. The changes were recorded by means of kymograph supplemented by TAMURA's attachment.

C. Methods for describing Blocd Pressure and Respiratory Movement:

Use was made of mature unanesthetized cats weighing around $2 \mathrm{~kg}$. A. carotis communis was opened and connected to the mercury manometer in one and the trachea was opened and connected to Marey's tambour in another. The solution of experimental substance was infused through either A. femoralis or ventral cavity and changes were recorded by means of kymograph.

\section{Experimental Results}

\section{A. Action of $C O R$ :}

(1) The fact that corcillin when used alone possesses high cardiotonic action is already reported. Here efforts were made to ascertain whether or not any changes would ensue when corcillin was subjected to the refining process. Therefore, the same test was repeated to substantiate the finding that it possesses in a normal heart a lasting amplitude by its addition of $0.1 \%$. When the Ringer solution inside the canule was renewed, the cardiac function gradually restored itself to the normal level (Fig. 1) and the change of the Ringer solution for three times was usually called for before a restoration takes place (Figs. 2, 3 and 4). When the heart was left for three hours inside the YAGI's apparatus, its amplitude decreased accompanied with some irregularities of pulse, bringing about the state of fatigue. The administration of $0.1 \%$ corcillin gave a sign of considerable restoration (Figs. 5, 6 and 7). It must be mentioned that throughout the present experiment $0.1 \%$ corcillin was always used.

(2) In order to look into the cardiotonic mechanism of corcillin, Ergocrine (a commercial anesthetic for the sympathetic end nerves) was diluted up to 10 times of the original by the addition of Ringer solution $0.03 \mathrm{cc}$ was used prior to corcillin for the sake of comparison (Fig. 7). As a result, the enhancement of amplitude was inhibited to a small degree (Fig. 8). When the amount of Ergocrine was increased to $0.06 \mathrm{cc}$ (Fig. 9) and $0.1 \mathrm{cc}$ (Fig. 10) respectively as pre-experimental treatment, the identical tendency of increasing the cardiac beat amplitude was observed at work. These findings point out to a possibility that the cardiotonic quality of this substance may be due to excitation on the part of the sympathetic end nerves. In a similar vein, after the corcillin effects were examined $0.06 \mathrm{cc}$ of $1.0 \%$ nicotine which works on the autonomic nerve-ganglion was applied on the same test heart (Fig. 11). The result of a comparison here again testifies to the same tendency as was the case with an anesthetic for the 


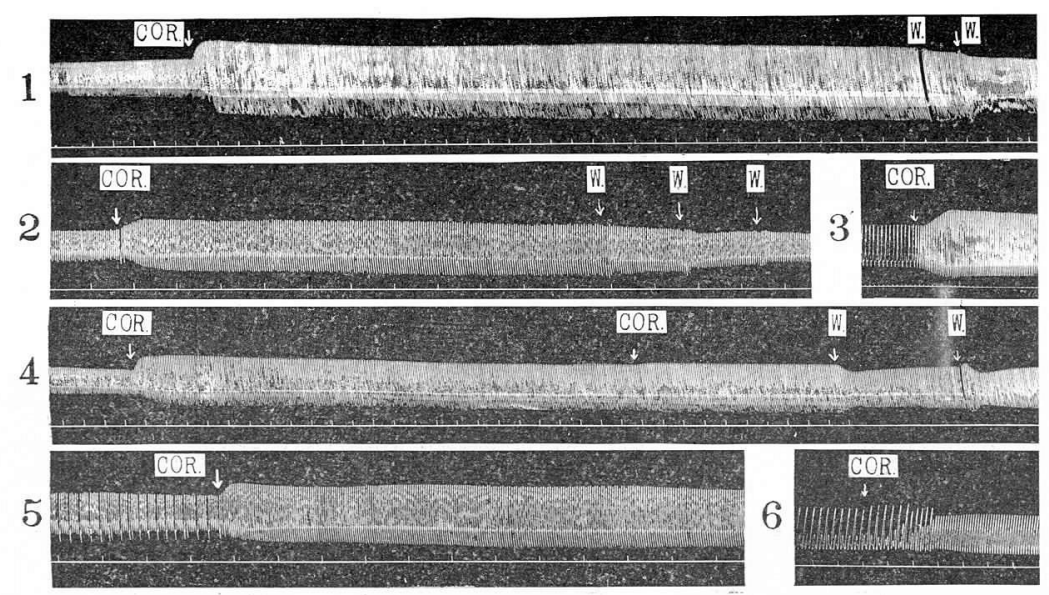

sympathetic end nerves (Figs. 12 and 13). In terms of these findings, it may be thought that the cardiotonic effects of corcillin is not due only to excitation of the autonomic nerve-ganglion.

When $0.06 \mathrm{cc}$ and $0.1 \mathrm{cc}$ of $1.0 \%$ potassium nitrate which is an anesthetic of heart muscles were respectively on the heart and corcillin was given afterward, no appreciable changes as against control took place (Figs. 15 and 16). From this fact it was known that the cardiotonic effects of corcillin is not due only to the excitation of heart muscles. Therefore, it was supposed that corcillin does not act singly on any one of the sympathetic end-nerves, autonomic nerve ganglions or heart muscles, but on these combinedly. Another test where $0.06 \mathrm{cc}$ nicotine and $0.03 \mathrm{cc}$ Ergocrine were premedicated confirmed the above view and it was known that in the cardiotonic effects of corcillin the excitation of autonomic nerve ganglions plays a chief role, sympathetic end-nerves and heart muscles participating secondarily (Fig. 17).
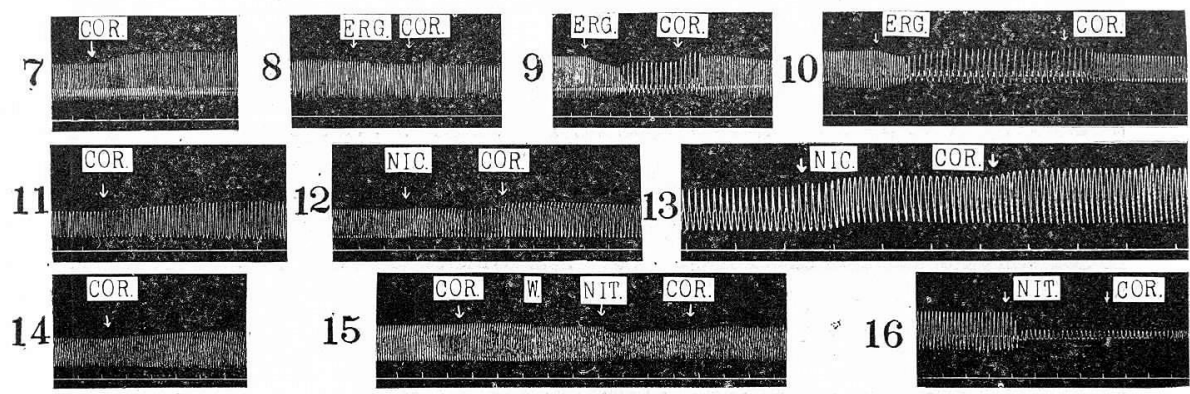

15
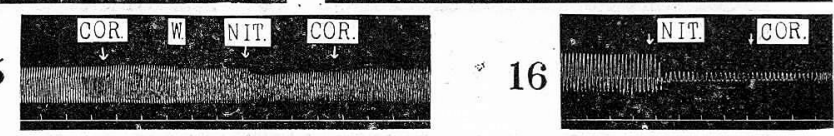

When barium chloride which is an excitatory drug of heart muscles was administered to see whether it would work conjointly with corcillin, $0.1 \mathrm{cc}$ of $1.0 \%$ barium chloride failed to give any indication of conjoint effect (Fig. 19). In comparison with the case where epinephrine was used alone (Fig. 20), it was proved that epinephrine with corcillin premedicatively used had somewhat better result in terms of cardiotonic action (Fig. 21).

(3) With a view to lcoking into the stability of corcillin in the state of water 
solution, a sample was left at room temperature $\left(21^{\circ} \mathrm{C}\right.$ in the month of June) crod another was stored in an ice bath at $4^{\circ} \mathrm{C}$ for 15 days respectively (Figs. 22 and 23). However, no changes were detected between the two samples and they gave the same effects as those of freshly prepared corcillin. Another test of physical changes in the effect of corcillin which was left in running water for 24 hours showed no difference (Fig. 24).

B. Action of CPGS :

(1) 200,000 unit crystalline penicillin G sodium was solved in 1cc of Ringer's
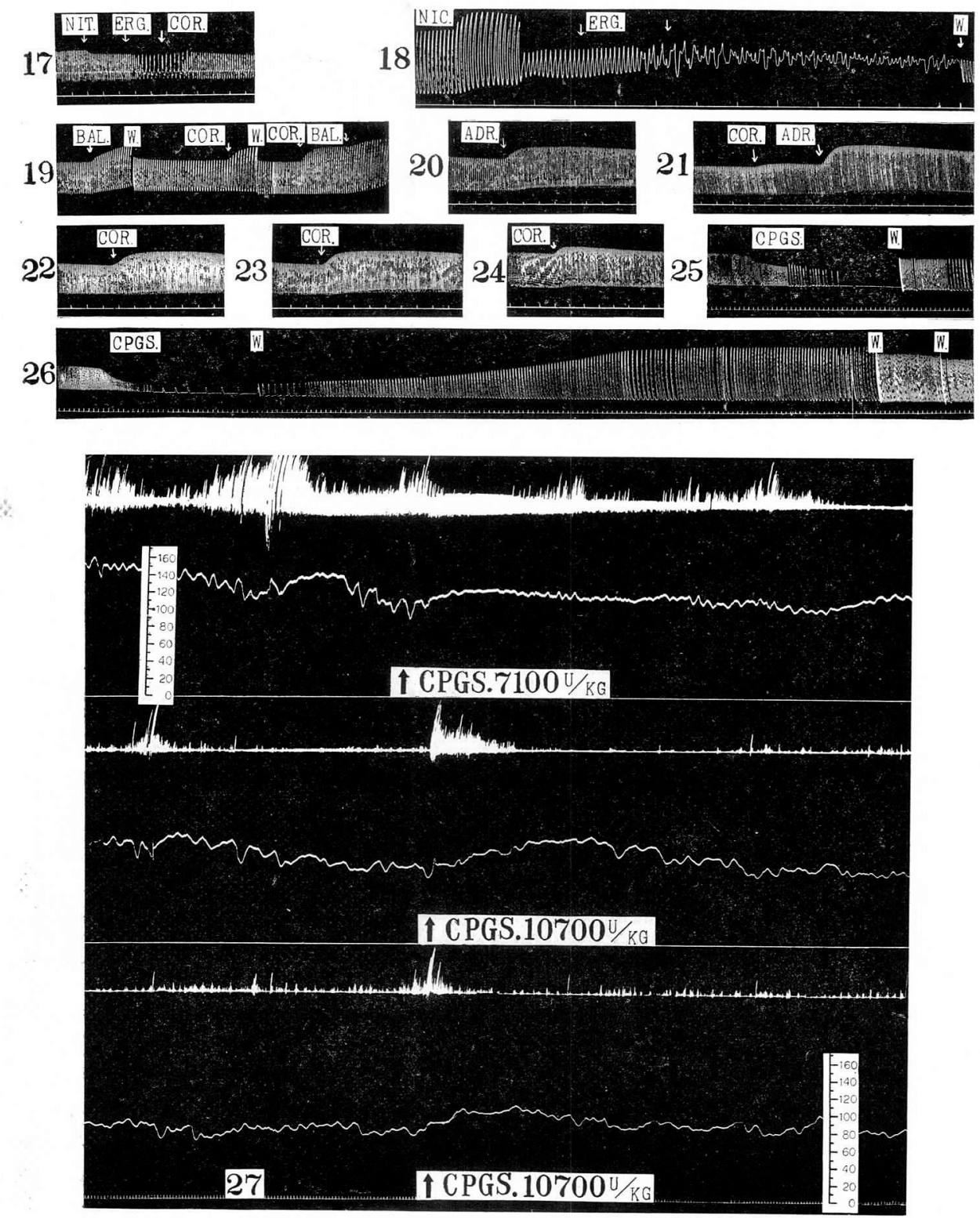
solution for cold blood animals and when $1 / 10$ of its was dropped on the specimen heart, there took place very active cardiac inhibition accompanied with decrease in amplitude, decrease in pulse beat or sometimes loss of movement. As contrasted against 40 counts in amplitude per minute prior to medication, it went down as low as 16 counts after medication. Repeated exchange of Ringer's solution was instrumental in bringing back the normal amplitude gradually (Fig. 26). This definitely establishes an inhibitory effect of crystalline penicillin $G$ sodium on heart function.

(2) Another 200,000 unit preparation of crystalline penicilln $G$ sodium was solved in $0.5 \mathrm{cc}$ Ringer's solution and an injection with a ratio of $7100 \mathrm{U} / \mathrm{kg}$ was effected intra-arterially in an attempt to investigate its effects on the A. carotis blood pressure and respiratory movement. As a result, the blood pressure slightly went down and the respiratory movement came to be gradually inhibited. After 20 minutes, the same crystalline penicillin G sodium was mixed with GL-127, GL-111 and GL-116 and was intra-arterially injected. A rise of $30 \mathrm{~mm} \mathrm{Hg}$ column soon occurred after 4 minutes but a further addition of the same drugs brought about a similar rise (Fig. 27).

When only crystalline penicillin $G$ sodium was administered at a ratio of 25,000 $\mathrm{U} / \mathrm{kg}$, a decrease in the blood pressure by $20 \mathrm{~mm}$ and after the duration of 4 minutes
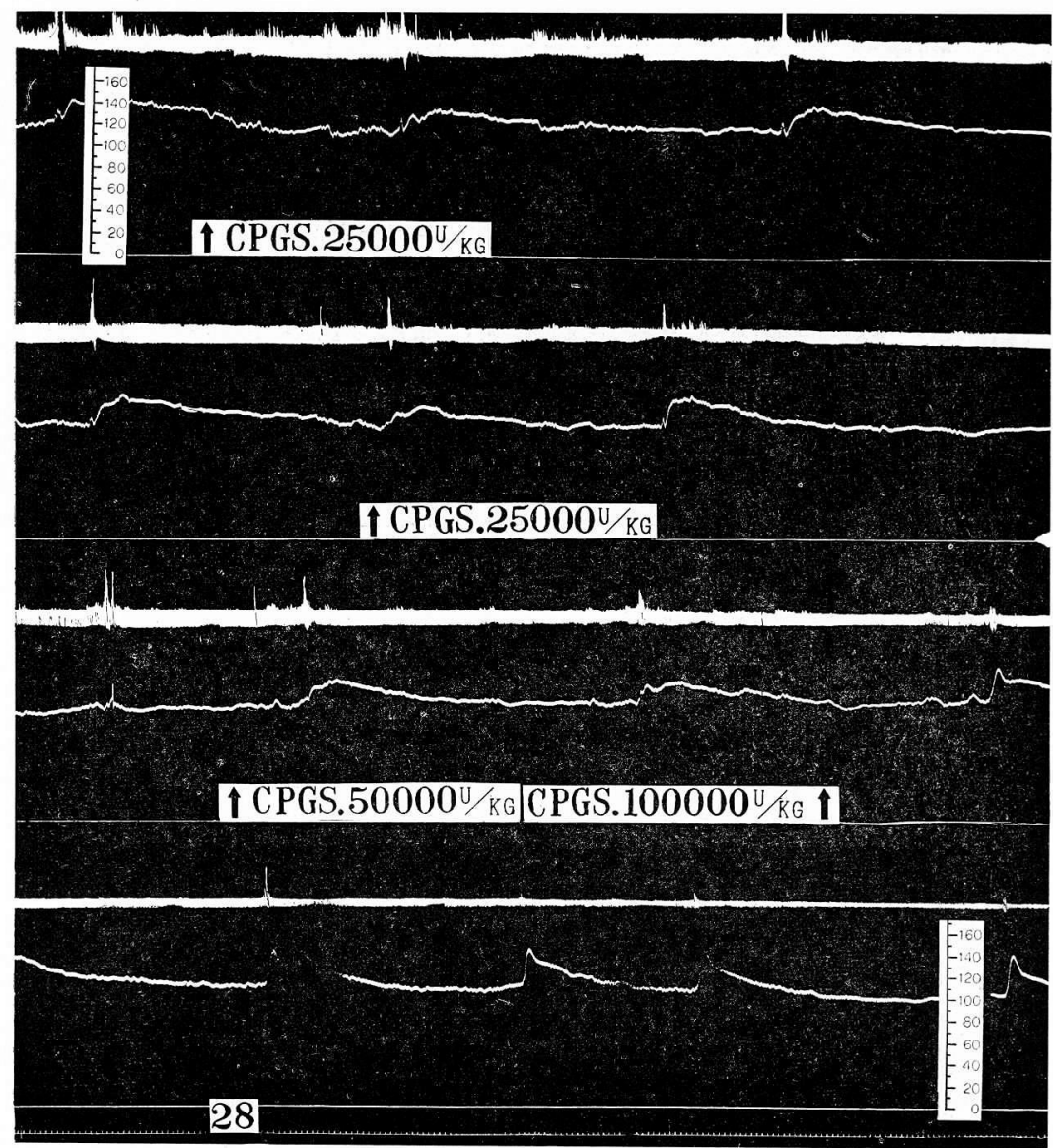
it reverted to the normal level. The administration of another dose in the same amount, $50,000 \mathrm{U} / \mathrm{kg}$ (17 minutes later) and $100,000 \mathrm{U} / \mathrm{kg}$ injection of an admixture of G-364 and GL-114 showed a mere result of gradual inhibition of the respiratory movement (Fig. 28). Although there were observed transitory rises of the blood pressure at an interval of a few minutes, we could not determine whether this was ascribable to the peculiarity of crystalline penicillin G sodium. In the case where an injection of 200,000 U/kg GL-151 was effected from the outset, there also took place a rise in the blood pressure (about $40 \mathrm{~mm} \mathrm{Hg}$ column) of transitory nature (Fig. 29). This phenomenon

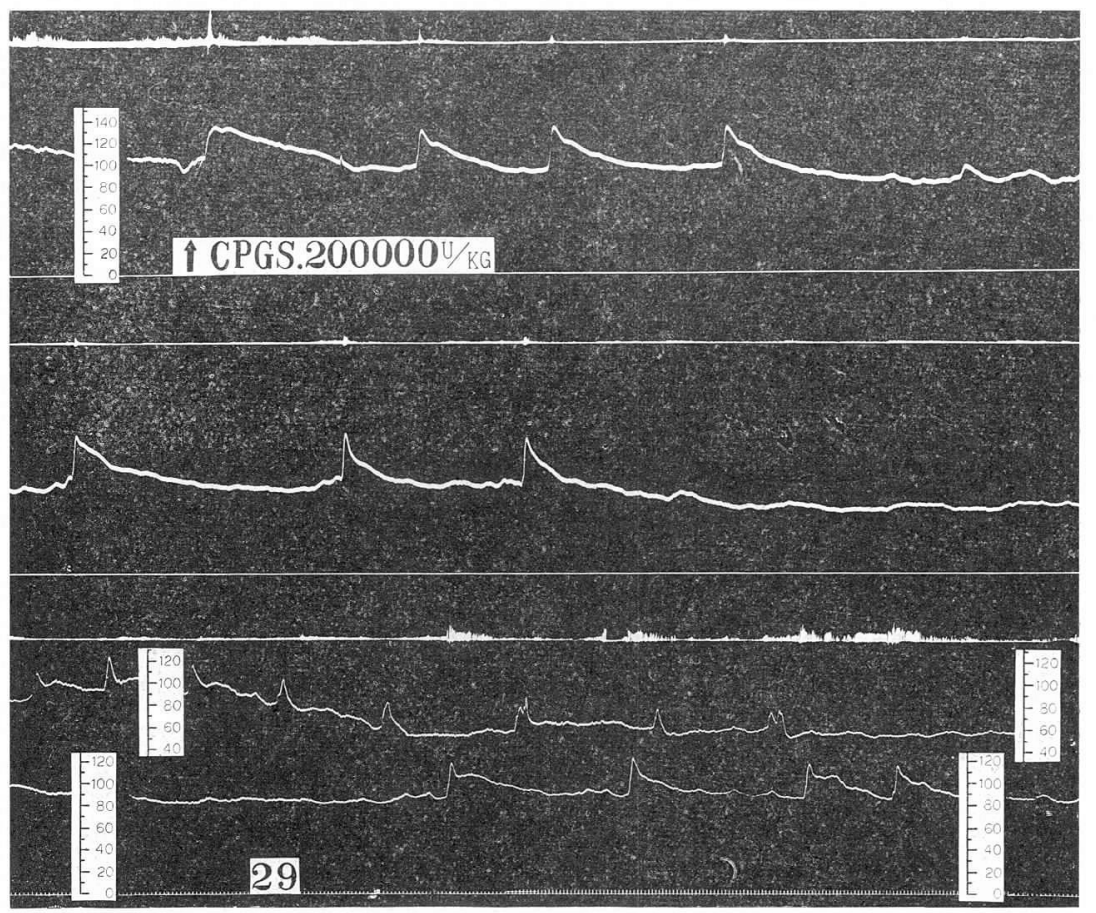

was true of 12 unanesthetized experimental cats and though we could not find sufficient justification for this, it was thought to be of some interest. With $35,000 \mathrm{U} / \mathrm{kg}$ injection there were cases where a rise by $20 \mathrm{~mm}$ continued as long as for 60 minutes with the accompanying tendency of respiratory inhibition (Fig. 30).

When 1,071,000 U/kg of 300,000 unit crystalline procaine-penicillin in oil, containing $2 \%(\mathrm{~W} / \mathrm{V})$ alminum monosterate, was injected intraventicularly, a gradual decrease in the blood pressure began to take place after 4 minutes reaching $43 \mathrm{~mm} \mathrm{Hg}$ column in 32 minutes, suddenly reverting from this terminal point to $8 \mathrm{~mm} \mathrm{Hg}$ column above the normal (Fig. 31).

With $50,000 \mathrm{U} / \mathrm{kg}$ of CPGS there took place $15 \mathrm{~mm}$ to $35 \mathrm{~mm} \mathrm{Hg}$ column rises with the periodicity of 30 seconds and after a violent inhibition of respiratory movement some of light-weight cats died (Fig. 32).

Based on the findings of these experiments, it may be generalized that an injection of CPGS into unanesthetized cats does not bring about uniform changes in the blood pressure of $A$. carotis, showing an upward tendency in some cases and downward 

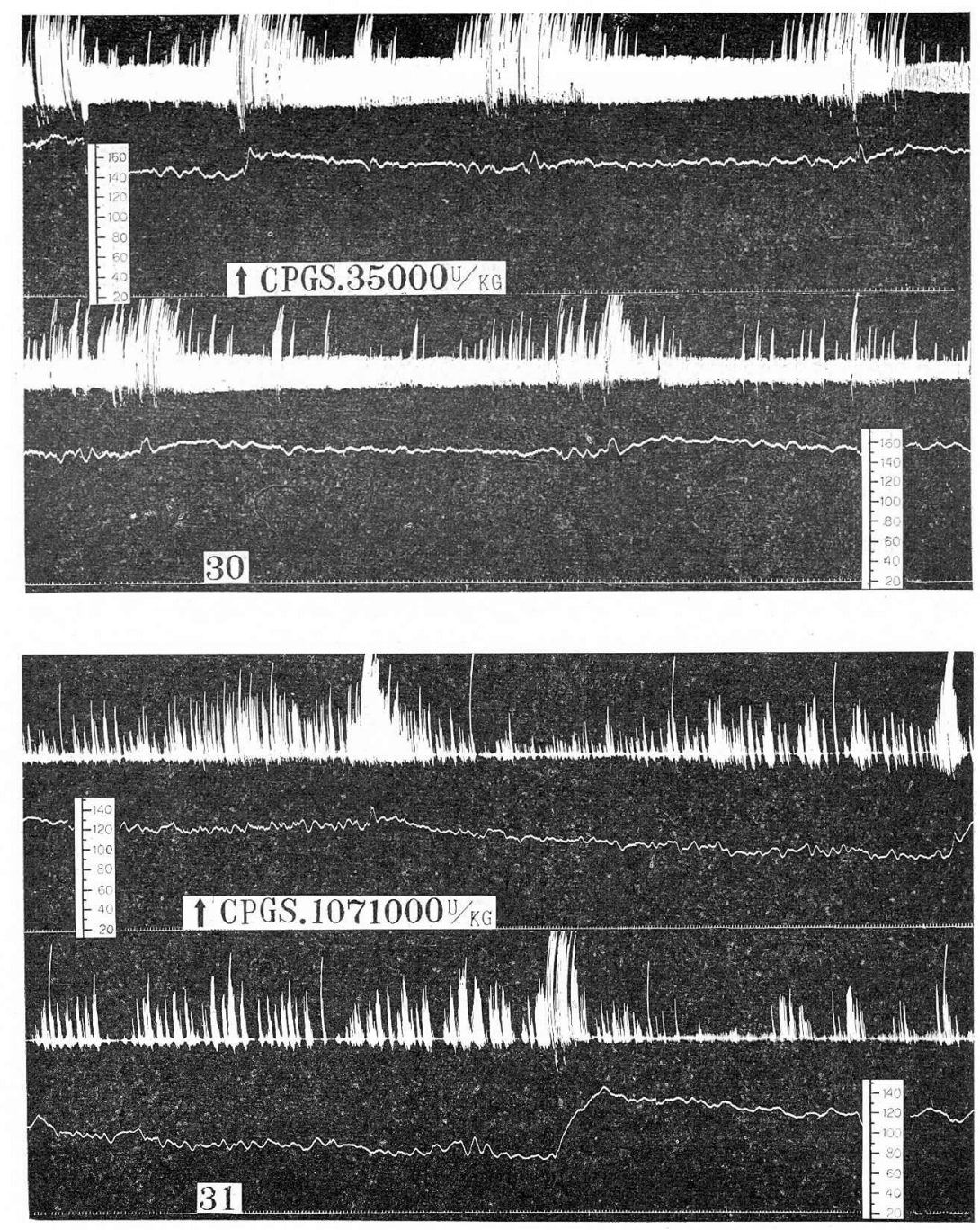

tendency in others. As for the inhibition of respiratory movement, however, the inhibition took place in almost every case. Our Department is now conducting a comparative study on the effects of corcillin and crystalline penicillin G sodium concerning the blood pressure inhibition and cardiotonic properties, and we expect the results to be shortly published.

\section{Conclusions}

A substance contained in penicillin which was suspected to possess possible cardiotonic effects was examined in terms of the heart extracted from toads and, at the same time, the cardiac function of penicillin itself was looked into with cats for their changes in blood pressure and respiratory movement. As the conclusion thus reached, the 


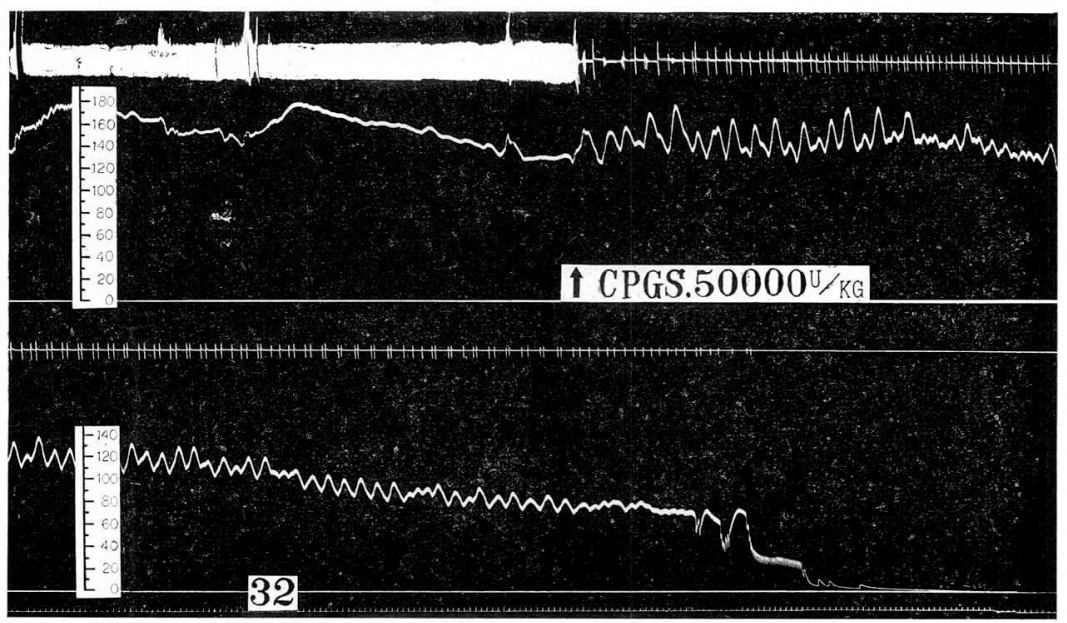

following findings are to be given. As the premedicative administration of a sympathetic nerve-end anesthetic (Ergocrine), an autonomous nerve-ganglion anesthetic (nicotine) and a heart muscle anesthetic (potassium nitrate) respectively failed to check the cardiotonic effects of this substance, it has become clear that it does not work on any one of these drugs. As far as the present series of experiments are concerned, it may be supposed that certain degrees of all three drugs are concerned in this seeming complicated of cardiotonic mechanism of this substance contained in penicillin, provisionally designated corcillin. This substance is also known to work co-operatively with a certain specific amount of ephedrine which excites the sympathetic nerve ends.

On the other hand, the solution of crystalline penicillin G sodium in Ringer's agent for frogs failed to induce any change in the blood pressure of unanesthetized cats but the general tendency was observed at work to inhibit their respiratory movement.

\section{References}

1) Murakami, R. et al. : Antibiotics and Cancer (in Jap.), Japanese Medical Journal, No. 1797, 19 (1958)

2) Nakazuka, M. : Chemical Therapeutic Drugs (in Jap.), p. 289, Medical, Dental and Pharmacological Publishing Co. (1956)

3) Tamura, T. et al.: A Pharmacological Study on a Substance extractable from Penicillin and its Cardiotonic Action (in Jap.), Shika-Geppo, Vol. 30, No. 3 (1957)

4) TAmura, T.: We can make a better recording machine made with a saw only (in Jap.), Medicine and Biology, 222 (1951)

5) Mryakawa, K.: On the Undulatory Change of the Blood Pressure Level and Periodical Change of the Respiratory Pattern elicited by Control of Brain Circulation (in Jap.), Journal of the Physiological Society of Japan, Vol. 17, No. $6: 383$ (1955)

6) Ogasawara, I. : The Third Type of Fluctuation in Blood Pressure (in Jap.): Part 1, the Effect of Vagal Nerves, Journal of the Physiological Society of Japan, Vol. 17, No. 1:16 (1955)

7) Ogasawara, I. : The Third Type of Fluctuation in Blood Pressure (in Jap.): Part 2, its Short Periodicity and Brain Stem Reticular Formation, Journal of the Physiological Society of Japan, Vol. 20, No. $6: 382$ (1958) 